\title{
Policies for Teachers towards Errors in College English Writing
}

\author{
Sixia Gao \\ Foreign Languages School, Qingdao University of Science and Technology \\ Qingdao 266061, China \\ E-mail: agnes0126@sina.com
}

\begin{abstract}
Errors made by language learners in learning a language are regarded as failure of competence. Linguists believe that errors are committed when the learner makes use of the learning strategies. By analyzing the learner's errors, we can better understand his inter-language and his learning process. It's necessary to understand the roots of errors before they are eliminated. Students' misuse in vocabulary and grammar demonstrates that teachers should pay more attention to the reinforcement of knowledge delivered to the students. Only in this way will students' abilities be improved effectively.
\end{abstract}

Keywords: Errors, College English writing, Language learning

\section{Introduction}

In the 1950s and early 1960s, the prevailing technique used in the study of errors of L2 learners had been Contrastive Analysis(CA). The rationale for CA lies within behaviorism and the belief that learning is a question of habit formation (Johnson 2001). The behaviorists believed that old habits would have some effects on the learning process of a new habit, which is known in psychology as transfer. In the case of language learning, it is believed that the learner's first language affects his or her L2 learning, either facilitating the learning process when the two languages share common aspects or hindering it when there are differences. CA as applied to L2 teaching is pedagogically-oriented, with the aim to discover and predict learning problems and difficulties.

With the birth of psycholinguistics and the shift of focus in language learning from being teacher-centered to learner-centered, the application of Error Analysis (EA) has been developed. According to S.P. Corder (1981:16), EA, as a scientific technique based on psycholinguistics, is a type of bilingual comparison; a comparison between learners' inter-language and the target language. Brown (1987: 169) argues that 'the study of the speech of learners is largely the study of the errors of learners', because 'correct items yield little information about the L1 of the learner'. Error Analysis (EA) is based on the assumptions that errors made by L2 learners can be predicted, observed, analyzed, classified and described (Brown 1987).

\section{Brief review of theories about errors}

A clear distinction has to be made between what errors are on the one hand and what mistakes are on the other hand. The error versus mistake distinction was introduced into modern debates by Corder(1967), who first advocated the importance of errors in language learning process. In identifying errors, it is necessary to draw a distinction between those errors which are the products of chance circumstances, and those which reveal the learner's underlying knowledge of the process of language learning, because they are random and non-systematic, and they are induced by many factors, whereas the latter are errors of competence or errors, which are worth studying and analyzing, because they reveal the learner's knowledge of the target language, or his transitional competence. Dulay et al (1982:139) use the term 'error' to refer to any deviation from a selected norm of language performance, no matter what the characteristics or causes of the deviation might be. James (1998) uses the neutral term deviance(s) for all ways of being wrong as a foreign language learner and divides deviances into four types: slips, mistakes, errors and solecisms. According to James (1998), slips can quickly be detected and self-corrected by their author unaided. Mistakes can only be corrected by their author if their deviance is pointed out to him or her. Errors cannot be self-corrected until further relevant (to that error) input (implicit or explicit) has been provided and converted into intake by the learner. Solecisms are breaches of the rules of correctness as laid down by purists and usually taught in schools. In this paper, the term 'error' is used to refer to the deviation or unsuccessful language which the learner produces and fails to correct automatically. In this sense, what we call errors include what James calls mistakes, errors and solecisms.

\subsection{The relationship between learning and teaching}

According to behaviorism, 'learning is a relatively permanent change in a behavioral tendency and is the result of 
reinforced practice (Kimble \& Garmezy 1963:133). As we all know, human beings differ greatly from animals in learning, especially in language learning which is unique to human beings. According to psychologists, cognitive learning (the acquisition and organization of meaning) is exclusively a human activity. It is a process of getting to know the outside world through understanding and deduction.

Teaching can be defined as 'activities which are intended to bring about learning' and 'teaching cannot be defined apart from learning' (Brown 1987:7). The task of teaching is to guide and facilitate learning, to provide conditions for the learner to learn and to speed up the process of learning. Just as J.S. Bruner (1966:44) says, 'learning something with the aid of an instructor should, if instruction is effective, be less dangerous or risky or painful than learning on one's own'. Therefore, a qualified language teacher is supposed to understand how language learning takes place, how the learner learns and develops and what strategies are adopted by the learner, and to be capable of using this appreciation to coordinate knowledge with skill. The language teacher's understanding of his task determines his teaching style, approach, methodology and ultimately the success or failure of his teaching.

\subsection{Classification of errors}

According to James (1998), errors are classified by reference to three criteria: modality, medium and level. Modality refers to whether the learner's behavior is receptive or productive. Medium indicates whether the language produced or received is spoken or written. Taking modality and medium together, we are able to specify which of the 'four skills' the learner is operating at the time of the error: speaking, writing, listening or reading. In addition to this, we should also specify on what level of language the learner is operating at the time he or she makes the error. There are three levels of language: the levels of substance, text and discourse.

1) Substance errors: A misspelling (MS) is a substance level production error. There are other sorts of substance errors besides MSs that involve writing. They are referred to as mechanical errors (James 1998), including punctuation errors, typographic errors, dyslexic errors and confusables.

2) Text errors: According to James, the concept of text does not have to be restricted to grammar above the sentence, as once was customary in linguistics. Text is used in a much broader sense to designate any instance of language that results from applying the rules of encoding and of lexico-grammar(1998: 142). As Widdowson puts it: 'Texts can come in all shapes and sizes: they can correspond in extent with any linguistic unit: letter, sound, word, sentence, combination of sentences (1975:164).

3) Lexical errors: Lexis has been sharply differentiated from grammar. Grammar is said to be organized in 'closed' systems, to be systematic and regular. Lexis appertains to 'all the particular facts about language... those which cannot be generalized into rules' (Leech 1981:179).

\subsection{The significance of error analysis}

Reflecting learning process will show us that error analysis is of great significance. First of all, making errors shows the process in which learners are trying to perform the target language when they are learning. Learners are trying to learn English by receiving a lot of input, which is processed immediately and some knowledge is intaken and internalized, cumulating in their brains, later they attempt to express them either by speech or writing. When they try to convey what they have just learned, they can inevitably make errors in the course of output. According to Ellis (1985), error evaluation is necessary only if the purpose of the Error Analysis is pedagogic, because errors provide information which could be used to sequence items for teaching or to devise remedial lessons. L2 learners will benefit a great deal from overt correction of errors if it is constructive and meaningful.

\section{Recommended policies for teachers to have towards error}

In certain areas of English the learner possesses construction rules. But these rules give rise to errors of one kind or another, due to some kind of limitation in them. College English teachers should make it clear that the restricted generalizations employed by the learner are not of equal status, considering their error-causing potentialities. Those which are more productive of errors call for more attention and time and a more rewarding practice is to tackle the error-prone restricted generalizations instead of the mere correction of actual errors. As Corder (1967) claims, the 'input' in terms of learning the L2 system is not what is available for going in but what the learner takes in through his over-generalized rules. Therefore, before the correction of actual errors, special efforts from the teacher are demanded in establishing for the learner the limitation of rule generalization. In this way, correction of actual errors will have effect and will be rewarding.

Some basic grammatical items, such as English tense, should be reviewed, not through the teacher's explanation, but through error-based remedial program. Each assignment should be more target-oriented instead of blind practice, which is less efficient and more time-consuming.

\subsection{More attention to CE writing}

In both L1 and L2 learning, reading and writing do not develop simultaneously, with students' writing ability being too 
far behind their reading ability. As a result, it tends to hinder their overall development. To solve this problem, great attention should be paid to the use of the core words. The fact that a large number of errors result from the misuse of words from the same class, and from the mismatch of words proves that competence is as important as knowledge, or that the learner's procedural knowledge is not enough. To improve their performance, students need more opportunities to practice and teachers should offer more systematic and target-oriented teaching in writing. Students' errors on lexical level are various and do not seem entirely rule-based, therefore it is difficult for teachers to carry out correction aimed at eradicating lexical errors effectively. The use of one word may be a problem for one student, but a piece of cake for another student. It is rare that all learners produce the same error in the same context of use. So to find out the rule requires further, deep study. At the moment, we may say the study of errors on lexical level enables us to predict the possible errors some learners might commit in a specific context, which will bring the teaching of reading more closely connected with the teaching of writing and will ultimately help to improve the teaching of CE writing.

\subsection{Encouragement of learners' self-discovery and self-correction}

It is very important to offer students as many opportunities as possible to discover and correct errors. By doing so, we do not by any means imply that we will avoid adopting other ways of correcting errors, such as partner correction, group correction, the whole class correction and so on. The most important point is to encourage learners themselves to self-discover and self-correct errors that they have. The problem is that sometimes learners find it very hard to discover their own errors. In this case, hints and guides are needed from teachers in order to make error correction more affective and efficient (Makino 1993: 338).

It is clear that detailed cues lead to a higher ratio of self-correction. This technique of error correction has two advantages: one is that teacher's cues give students a chance to reflect on their writing and to pay more attention to the structural forms they have written; the other is that students can activate their linguistic competence in correcting their own errors. They also improve their linguistic creativity through self-correction. Therefore, we can reach the conclusion that self-correction is highly effective with grammatical (especially, morphological) errors.

\subsection{Knowledge reinforcement}

According to James (1998), consistency is a means to tell. Then most of the deviances are errors, which are committed repeatedly in different contexts and with different items, for example, the third person singular of the English simple present tense. But James (1998) also claims the deviances will be regarded as mistakes if the learner could have self-corrected, with or without prompting. Accordingly, a large number of deviances should be classified as mistakes which are normally excluded from study, because the students have no difficulties identifying and correcting the deviance once the sentences are picked out. This phenomenon happens more often on grammatical level than on lexical level. As we are more concerned with the practice of EA, rather than just theories, the problem may be regarded as a clue to how to make students improve their competence and be consistent in applying rules, as well as an indication that although students have learned rules in some areas of the language, they are limited in application or they merely understand the rules, there is still some work to be done for both teachers and students, before they can master the rules and put them in practice.

\section{Conclusion}

English, as the most popular foreign language in China, is one of the core subjects in the present six-year secondary education and is a compulsory subject for the first and second year university students. College students in China attach great importance to their improvement of communication skills in English. Unfortunately, due to various reasons, the situation is not so encouraging despite teachers and students' persistent efforts. For college English teachers, writing means extended working hours spent in correcting students errors. For students writing is boring because they can hardly see any improvement in their ability. In this paper, by reviewing research on error analysis, consulting James' model of error classification, the author explains the possible roots of the errors, offers some suggestions to enhance both the task of English writing and college English teaching in China.

\section{References}

Brown, H.D. (1987). Principles of Language Learning and Teaching ( $2^{\text {nd }}$ Edition). Englewood Cliffs, New Jersey: Prentice-Hall.

Bruner, J.S. (1966). Toward a Theory of Instruction. New York: W.W. Norton \& Co.

Corder, S.P. (1981). Error Analysis and Interlanguage. Oxford University Press.

Corder, S.P. (1967). The Significance of Learner's Errors. International Review of Applied Linguistics, Vol.5 No.4

Dulay, H., Burt, M. and Krashen, S. D. Language Two. Rowley, MA: Newbury House, 1982.

Ellis, R. (1985). Understanding Second Language Acquisition. Oxford: Oxford University Press.

James, C. (1998). Error in Language Learning and Use: Exploring Error Analysis. Pearson Education Limited. 
Johnson, K. (2001). An Introduction to Foreign Language Learning and Teaching. Pearson Education Limited.

Kimble, G.A. \& Garmezy, N. (1963). Principles of General Psychology (2 ${ }^{\text {nd }}$ edition). New York: The Ronald Press Company.

Leech, G. (1981). Semantics (2 $2^{\text {nd }}$ edition). Harmondsworth: Penguin Boods.

Makino, T. Y. (1993). Learner self-correction in EFL written compositions. ELT Journal 47/4: 337-341.

Widdowson, H. (1975). EST in theory and practice. English for Academic Study. ETIC Occasional Paper. London: The British Council. 